\title{
Erectile Dysfunction: Clinical and Epidemiological Aspects in Senegal
}

\author{
Yoro Diallo ${ }^{*}$, Racine Kane ${ }^{2}$, Saint Charles Kouka1, Boubacar Fall ${ }^{3}$, Cyrille Ze Ondo 3 , \\ Abdoulaye N'Diaye2, Adamson Phiri', Amadou Sékou Soumah1, Babacar Diao3, \\ Cheickna Sylla ${ }^{1}$ \\ ${ }^{1}$ Department of Urology, Faculty of Health Sciences, University of Thies, Thies, Senegal \\ ${ }^{2}$ Department of Urology, Principal Hospital, Dakar, Senegal \\ ${ }^{3}$ Department of Urology, Hospital Health Teaching Aristide Le Dantec, Dakar, Senegal \\ Email: "yorodiallo@hotmail.com
}

Received 13 July 2015; accepted 1 September 2015; published 4 September 2015

Copyright (C) 2015 by authors and Scientific Research Publishing Inc.

This work is licensed under the Creative Commons Attribution International License (CC BY).

http://creativecommons.org/licenses/by/4.0/

(c) (i) Open Access

\section{Abstract}

Introduction: The objective of our study was to analyze the clinical and epidemiologic aspects of erectile dysfunction in subjects with different comorbidities in Senegal. Patients and Methods: This was a retrospective study over a period of 2 years on patients who presented themselves for consultation for erectile dysfunction. The study was carried out in the regions of Dakar and Thies at the Ouakam geriatric center and the Saint Jean of god Hospital of Thies respectively. Results: We enrolled into the study $\mathbf{4 0 2}$ patients with erectile dysfunction. The average age of our patients was $47 \pm 5$ years. Patients aged more than 60 years were the most. The majority of our patients had less than secondary school level education, 211 in total representing $52.5 \%$ of the study population compared to $14.9 \%$ having post baccalaureate level. A large number of these patients had professional activities (53.3\%), followed by retirees $(29.6 \%)$. Polygamous patients were more in number (51.5\%). In our study sample, we registered 120 active smokers $(29.9 \%)$. A hundred and ten of our patients were sedentary for periods of 5 months to 22 years. The average length of time before seeking help for erectile dysfunction in our patients was 2.8 years. Severe erectile dysfunction was predominant in the smoking group (54.2\%) compared to $(9.9 \%)$ in the nonsmoking group. We found a large proportion of severe and moderate erectile dysfunction $(66.3 \%)$ and $(31.7 \%)$ respectively in diabetic than non-diabetic patients. Severe erectile dysfunction was more in hypertensive and diabetics. Severe erectile dysfunction was more present in hypertensive plus smokers $(83.9 \%)$ than in non-smoking hypertensive patients $(68.6 \%)$. Severe ED was found more in hypertension and diabetic subjects. Conclusion: Erectile dysfunction is most frequently related on one side to socio-environmental factors, and to co-existing comorbidities on the other side.

\footnotetext{
"Corresponding author.
} 


\section{Keywords}

\section{Erectile Dysfunction, Epidemiology, Risk Factors, Clinical}

\section{Introduction}

Erectile dysfunction (ED) or impotence is sexual dysfunction characterized by persistent or recurrent inability to develop or maintain a satisfying erection of the penis during sexual activity. It is a worldwide public health problem; close to hundreds of millions of menworldwide are affected with tens of thousands new cases every year [1]. Studies done from across the world indicate an increase in the incidence rate of ED with age [2] as well as a huge impact of ED on the quality of life for the patients [3]. Emergence and evolution of ED are influenced by presence of certain defects including diabetes, hypertension [3]. ED is perceived as a handicap to life with a low self-esteem effect often responsible for troubled interpersonal relationships between couples. The objective of our study was to analyze the clinical and epidemiological aspects of erectile dysfunction in subjects with different comorbidities in Senegal.

\section{Patients and Methods}

This is a prospective, transversal and descriptive study involving patients who came to consultation for ED. Our study period was 2 years (January 2012 to December 2013) at four different health institutions in the Dakar and Thies regions: Principal Hospital of Dakar, Grand Yoff general hospital, geriatric center of Ouakam and the saint Jean of God Hospital of Thies.

Inclusion criteria: subjects who were at least 18 years at the time of consultation for ED.

Exclusion criteria: Subject aged less than 18 years at the time of consultation and all subjects without ED complaints.

The study parameters were: age, geographic origin, ethnic background, religion, profession, level of education attained, marital, and marriage type status, past medical and surgical history, existing cardiovascular and or chronic diseases risk factors, the reason for and the time taken before consultation, vital signs and medications history. Data was collected using a questionnaire IIEF 15. It is total of 15 questions evaluating the degree of erectile dysfunction [4].

- Absent ED: $26 \leq$ score $\leq 30$;

- Mild ED: $22 \leq$ score $\leq 25$;

- Moderate to Mild ED: $17 \leq$ score $\leq 21$;

- Moderate ED: $11 \leq$ score $\leq 16$;

- Severe ED: $6 \leq$ score $\leq 10$.

Our patients did give their consent for this work. We obtained the University's Ethics Committee agreement.

The Reliability coefficient was fixed $\mathrm{p}<0.005$.

All data were treated on the R software and Microsoft Excel 2010.

\section{Results}

During this study period, 402 patients resenting with ED symptoms were recruited. Average of the group was 47 \pm 5 years extremes of 18 to 94 years. Patients over 60 years old were the most represented (34.3\%) Figure 1.

The origins of our patient was variable, with the biggest number coming from the Dakar region (46.8\%) followed by those from the regions of Thies, (13.7\%), Louga (12.2\%), Saint Louis (3.2\%) respectively.

Patients with a level of education less than secondary school represented $52.5 \%$ of the study population $(\mathrm{n}=$ 211) while $14.9 \%$ were those with a post baccalaureate level of education (Table 1 ).

At the time of or study, patients in some type of professional activity were the majority (53.5\%), followed by retirees (29.9\%) (Figure 2).

Patients from polygamous marriages were more (51.5\%) than monogamous and singles combined (48.5\%).

Our study registered 120, (29.9\%) active smokers. The number of packets per year varying from 2 to 15 per annum with an average of $12.25 \pm 3 \mathrm{P} / \mathrm{A}$. It is noteworthy that 98 patients (representing $24.4 \%$ ) were former 


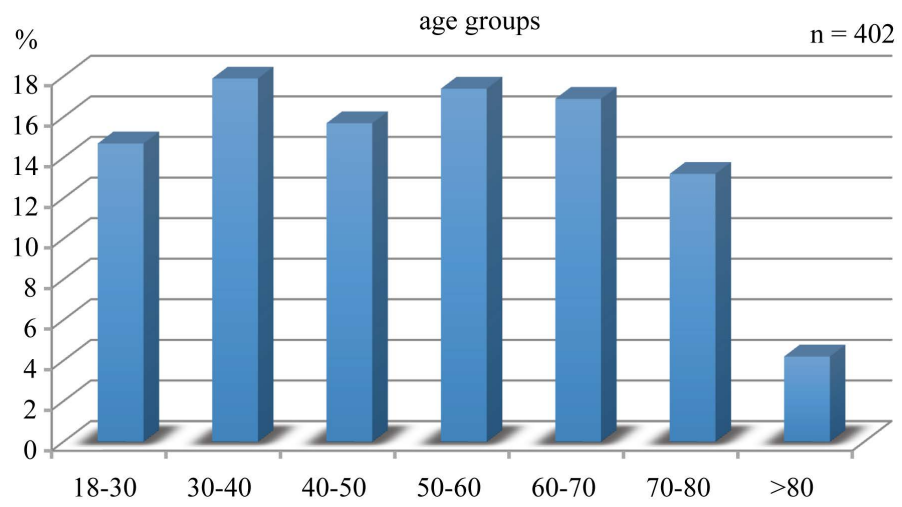

Figure 1. Distribution of patients by age.

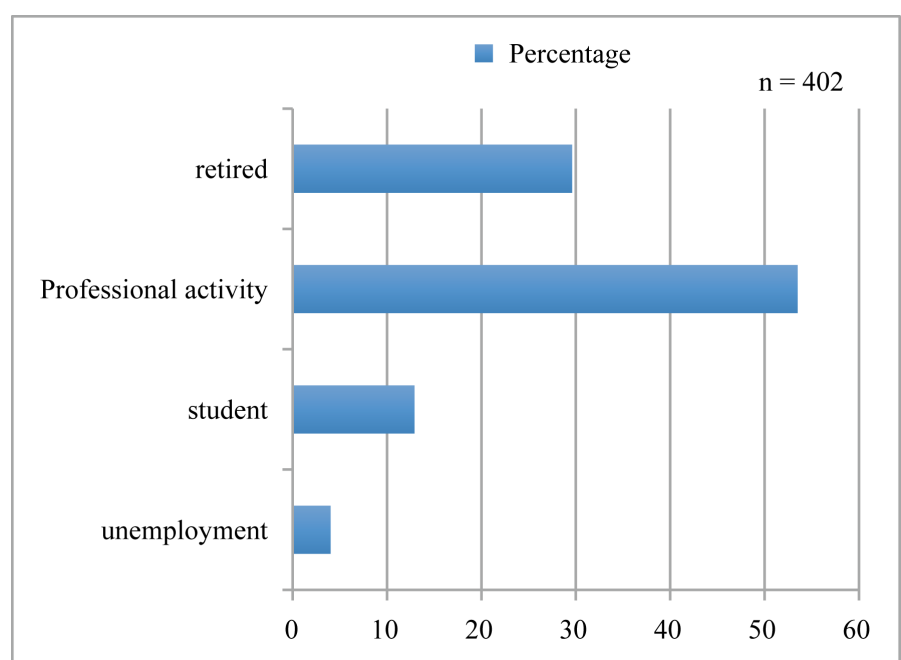

Figure 2. Distribution of patients according to their professional activity ED.

Table 1. Distribution of patients according to their grade ED.

\begin{tabular}{ccc}
\hline School level & Number of patients & Percentage (\%) \\
\hline Without & 62 & 15.4 \\
Koranic school & 44 & 10.9 \\
Primary & 105 & 26.2 \\
Secondary & 76 & 18.9 \\
Professional formation & 55 & 13.7 \\
Post BAC & 60 & 14.9 \\
Total & 402 & 100 \\
\hline
\end{tabular}

smokers. The weaning period from smoking was about 15 years with extremes of 1 to 33 years.

Alcohol consumption was noted in 53 of our patients (13.2\%). Quantities varying from $100 \mathrm{ml}$ to $1000 \mathrm{ml}$ per day, an average of $175 \mathrm{ml} /$ day.

In this study, 110 of the patients (27.7\%) were sedentary subjects. The periods of lack of activity ranging from 05 months to 22 years (Figure 3 ).

Significant medical and surgical history found in our patients included cerebral vascular accidents (CVA), Angina, myocardial infarction, cardiac valvular disease, keto acidosis, digestive tract and genital-urinary tumors, 
surgery of the hypogastria, perineal and the back (sciatica, inguinal hernias, varicocele, hydrocele, prostatic adenomectomy) (Figure 4).

Curtains medications which have ED as side effects were used by a wide range of study population. They included notably antihypertensives (Thiazide diuretics, non-selective beta blockers, and anti-depressants (Sertraline, Paroxetine).

ED was the principal cause for consultation in $83.1 \%$ of the cases while it was a secondary cause in $16.9 \%$.

The average period before seeking help for ED was 2.8 years with extremes ranging from 03 to 20 years. The majority of ED (57.7\%) had a characteristic insidious and intermittent onset and a recorded brutal onset in only $4.2 \%$.

Morning spontaneous erection was present in 306 of our patients (76.1\%) and non in 96 patients (23.9\%). In our study sample population the average sexual activity per week was in the order of 1.7 with extremes stretching to 8 . We studied rigidity and the length of erections in our patients. Lack of rigidity was the most frequent manifestation, (44.5\%), associated with brief erections in $25.1 \%$ of the cases. We noted a predominance moderate $(28.9 \%)$ as compared to mild and severe ED at $25.6 \%$ and $23 \%$ respectively. The principal sexual problems associated with ED were, loss of libido (47.8\%) and premature ejaculation at (29.9\%).

A very small proportion of our study population (21.9\%) informed and or discussed ED with their spouses. Traditional remedies were used by $49.5 \%$ of our patients followed by the use of vitamins and other anti-fatigue

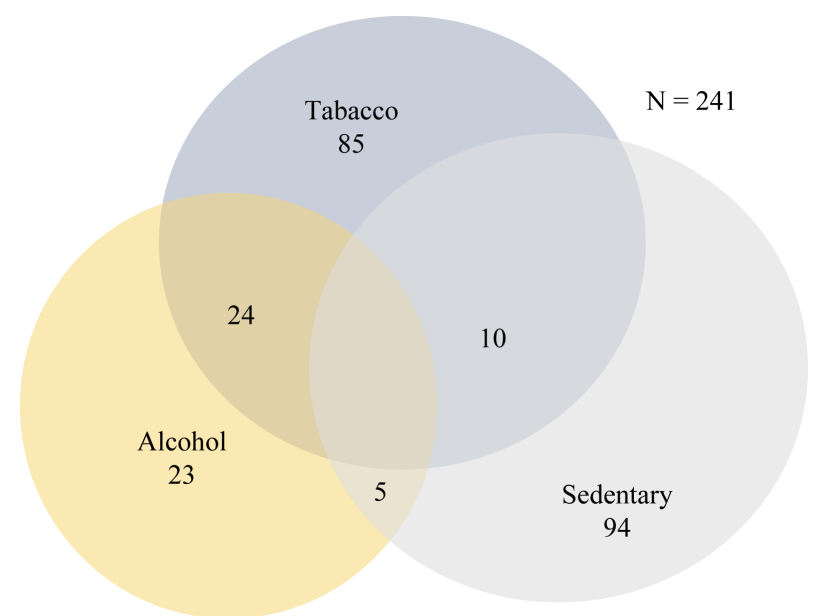

Figure 3. Proportions between tobacco, alcohol abuse and physical inactivity.

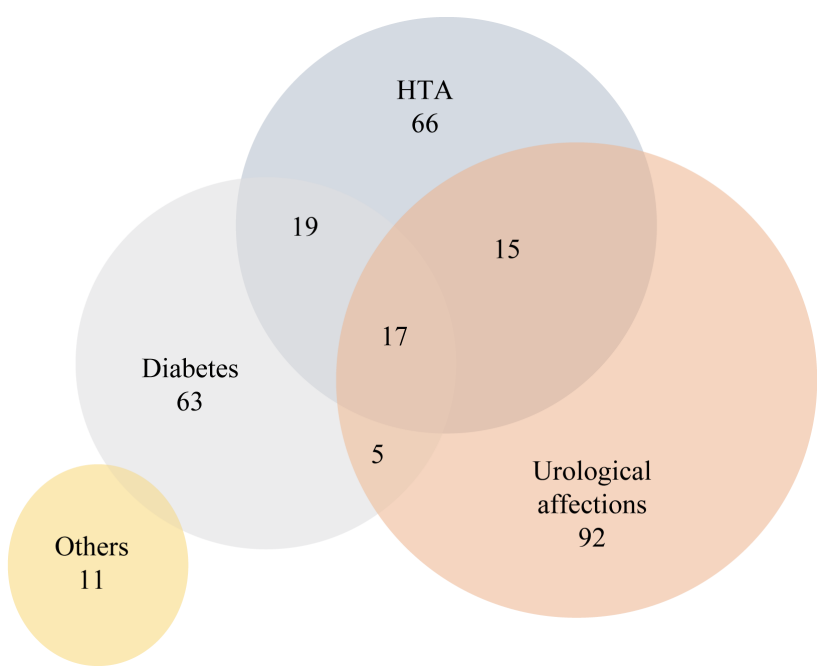

Figure 4. Proportions between pathology other than ED found in our study. 
medicines (38.3\%). Among the dysfunctional drugs per say, procomil spray was the most utilized than the phosphodiesterase-5.

Our sample size was a total of 402 patients. All of them did present with ED according to the I.I.E.F 15 scoring system. This system grades the severity of ED.

We did study the impact of certain epidemiological and clinical factors on the severity of ED.

The redistribution of severe ED according to different groups showed an increase in the rates of severe and moderate ED (3.4\% to $45.3 \%$ ), and (13.6\% to $54.3 \%$ ) respectively with age, while decreasing in moderate to mild ED ED was more predominant in smoking subjects (54.2\%) than in nonsmokers (9.9\%) It was the reverse for moderate to mild and mild.

The proportions of severe and moderate ED were higher in sedentary than non-sedentary subjects.

We found that diabetic patients had a higher proportion of severe and moderate ED than non-diabetics, $(66.3 \%)$, and $(31.7 \%)$ respectively- $(\mathrm{p}=0.2133)$.

Mild and, moderate to mild ED, was not encountered in hypertensive patients. Severe ED, however, was the most frequent in high blood pressure patients with $72.6 \%$ more than in non-hypertensive patients at $2.8 \%$.

There was a dominance of severe ED (72.7\%) in patients with severe to moderate HBP as compared to patients with mild ED (27.3\%).

Severe ED was found more in subjects with high blood pressure and diabetes (75\%) than in non-hypertensive, non-diabetic patients (2.8\%) (Figure 5).

Severe ED was more in present in smoking and hypertensive subjects (83.9\%) than hypertensive nonsmoking subjects (68.6\%). We did not find severe ED in non-hypertensive, nonsmoking subjects (Figure 6).

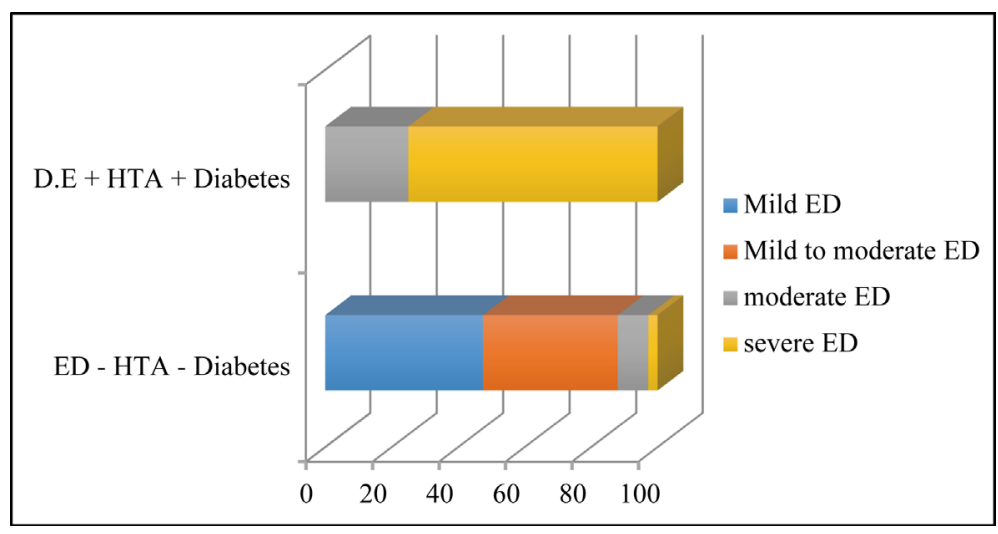

Figure 5. Distribution of patients according to the severe of ED and hypertension and diabetes.

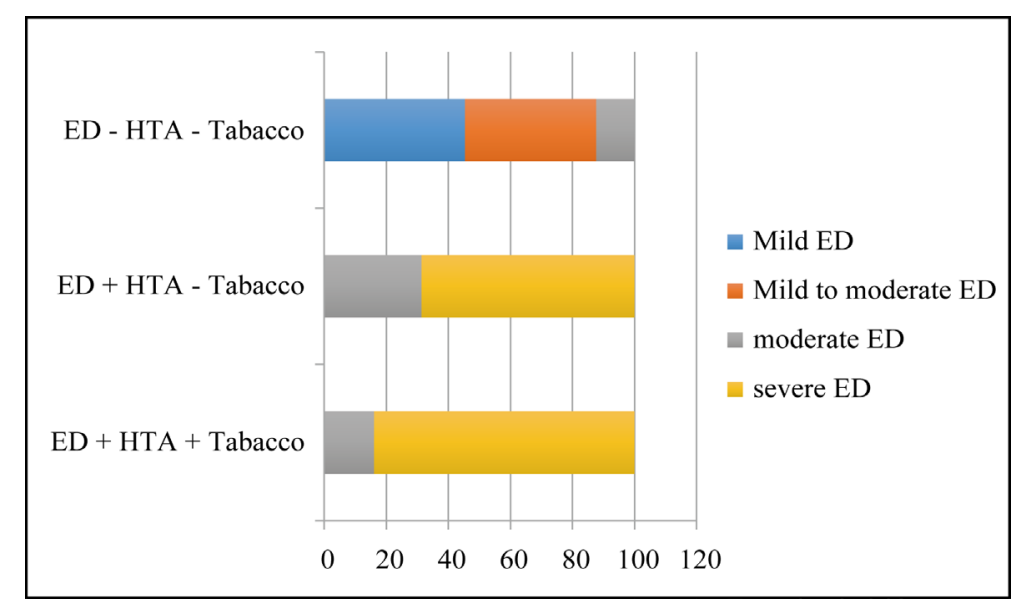

Figure 6. Distribution of patients according to the severe of ED and HTA and tobaccos. 


\section{Discussion}

The average age of a study population will vary depending on the country. In our study, it stands at 47 years. Diallo [5] found an average age of 62 years. This difference in age is justified by the diverse zones of study.

The rate of ED increases with age in our study. Our results are similar to those of Djorolo [6] who found a progressive increase in general ED rates with age. The rate of ED increases with age in our series. Our results are similar to those of Djorolo [6] who found a gradual increase in the overall rate of ED with age. In France, Costa [7] found a high prevalence of ED (25\%) correlated with age. In the US, Selvin [8] revealed a significant difference in the prevalence of ED according to age group. The survey Ab Rahman [9] in Malaysia on a middle-aged population 54.7 years found a prevalence of ED to $69.49 \%$ in men from 40 years and this rate increased with age.

The distribution of the severity of ED by age group varies according to the authors. Siu [10] Hong Kong, Giuliano [11] in France have found a statistically significant and steady increase of ED with age and increases in severity with age. These results could be explained by the natural aging process of vascular tissue and the increased presence of comorbidity at older ages.

For geographic origin, our results are similar to those of Diao [12] and Diallo [5] for which the most patients were from urban areas. These results are related to lifestyle and quality of life in large cities that are polluted usually stressful with a less healthy diet than in rural areas.

The occurrence of ED is influenced by the level of education. Our results are somewhat similar to those of Diallo [5] who found that $23.11 \%$ of patients hadhigher education. Unlike Diao [12] who obtained superimposable results with ours. ED rate decreased with increasing educational level. Elsewhere, the bi variable study by Akkus [13] in Turkey finds non-enrollment as a factor of ED. The investigations Selvin [8] revealed a significant association between ED and lower educational levels. In Malaysia, Ab Rahman [9] obtained opposite results; $65.5 \%$ of his patients had at least a high school education.

Professional status has an influence the occurrence of ED. In fact the majority of our patients had some sort of business activity (53.5\%). This could be explained by the importance of occupational stress. However, Diao [12] and Diallo [5] had found more ED in the retired population, (63.8\% and 62\%) than in the working group (30.6\% and 38\%) respectively. Akkus [13]; Ab Rahman [9] had noted a positive correlation between joblessness (unemployment and/or retirement) and the prevalence of ED.

In our series, polygamous men were the most represented. Diao [12] had found more polygamous men in his study population and found that the severity of ED increases with the number of wives. Akkus [13] found after by being separated, divorced or widowed was a risk factor for ED without giving results on the effect with the number of wives.

Tobacco is a predisposing factor to ED and an aggravating factor in the same. Diao [12] reported that the rate of ED increases with the duration of the tobacco intoxication, without any correlation with the severity objectified. Scarneciu [14] in Romania did demonstrate that smoking favored the occurrence of ED and that even passive smoking had an impact on the ED. Other authors [11] also reported deleterious effects of smoking on erectile function. The analysis of ED traits with physical inactivity in mind revealed a greater proportion of severe ED in sedentary than non-sedentary subjects. Selvin [8] reported a slight increase in prevalence of ED in huge sedentary subjects.

The study of the severity of the ED with diabetes showed a rise in the rate of severe and moderate ED in diabetic subjects compared to non-diabetic. Diabetes is triggering as well as an aggravating factor of ED [9]. Gueye [15] showed a correlation between the occurrence of the ED and the duration of diabetes but did not find any difference in the occurrence of ED with the types of diabetes. Some authors [16] reported that ED is more common in type 1 diabetes than in type 2 diabetes and that this difference persist after ageeffect adjustment. Weinberg [17] states that ED increased with duration of diabetes. Kolodny et al. [18] contrally did not find a link between the occurrence of ED and duration of diabetes. According to these authors, $12 \%$ of subjects diagnosed with ED had never beendiabetic. In Brazil, Moreira [19] found an incidence of ED higher in diabetics.

Our study revealed a strong correlation between ED and hypertension. Ossou-Nguiet [20] as well as Vlachopoulos [21] have found a link between the severity of ED and the severity of cardiovascular disease in general. For Banks [22] the severity of ED increases gradually with that of cardiovascular diseases. Diallo [5] in his series did not find a significant difference in the prevalence of severe ED between hypertensive and normotensive. 
Akkus et al. [13] found a positive association between HBP and onset of ED in both bi and multi varied analysesseveral other studies have shown varying degrees of hypertension as a trigger factor of ED [19].

The combination of several cardiovascular risk factors affect the severity of ED. Diao [12] found a rate of moderate ED multiplied by two in hypertensive-smoking versus nonsmoking hypertensive. Ridwan [23] showed that the rate of ED correlated to the number of cardiovascular risk factors.

The management of ED experienced delays, often due to lack of patient information and/oruncomfortable feeling when seeking medical help for this disorder. According to Costa et al. [6] it is quite rare to see GPs talk freely about it.

The ED is related to certain types of events such as existing anxiety and marital conflict which explains the existence of a significant psychologicalcontribution. Some authors [14] consider erectile dysfunction as a complex and multifactorial disease closely related to the emotional, cognitive and behavior of both the individual and his partner. Study of Low [24] in Malaysia found that women viewed with suspicion, distrust and fear the possibility that their husbands began treatment with IPDE-5 and would prefer that their husbands discussed with them beforehand.

The ED is under medicalized because of the pivotal role played by traditional herbal medicine in our sociocultural context and the equally important place of self-medication [25].

\section{Conclusion}

Erectile dysfunction (ED) has remained a major concern for men across the decades. More than just a harmless symptom of a transient disturbance, ED is often the cause of profound mental disorders and destabilizes the couple. Numerous studies conducted on this subject over the years have led to a better understanding of its pathophysiology. Better information of the population on the prevention and management of vascular risk factors help limit the occurrence of ED. Multidisciplinary interchange is a prerequisite condition to its optimal management.

\section{Conflict of Interest}

There is no conflict of interest.

\section{References}

[1] Solomon, H., Man, J.W. and Jackson, G. (2003) Erectile Dysfunction and the Cardiovascular Patient: Endothelial Dysfunction Is the Common Denominator. Heart, 89, 251-253. http://dx.doi.org/10.1136/heart.89.3.251

[2] Calvet, C., Martin, K., Robert, G., Moore, N., Eftekhari, P., et al. (2007) Treatment of Erectile Dysfunction by Inhibitors of Phosphodiesterase-5 and Eye Disorders by Anterior Ischemic Optic Neuropathy Non-Arteritic (NOIAN). Progress in Urology, 17, 920-927. http://dx.doi.org/10.1016/S1166-7087(07)92389-1

[3] Bonierbale, M. (2009) De la difficulté Sexuelle à la dysfonction Sexuelle. Sexologies, 18, 28-31. http://dx.doi.org/10.1016/j.sexol.2008.07.004

[4] Rosen, R.C., Riley, A., Wagner, G., Osterloh, I.H., Kirkpatrick, J. and Mishra, A. (1997) The International Index of Erectile Dysfunction (IIEF): A Multidimensional Scale for Assessment of Erectile Dysfunction. Urology, 49, 822-830. http://dx.doi.org/10.1016/S0090-4295(97)00238-0

[5] Diallo, Y., Coume, M., Ze Ondo, C., Diao, B. and Sylla, C. (2012) Erectile Dysfunction: Epidemiological Profilein Subjects Retired Population in Senegal. Andrology, 22, 241-245. http://dx.doi.org/10.1007/s12610-012-0200-5

[6] Djorolo, F., Amoussou-Guenou, D., Wanvoegbe, A. and Akpo, C. (2004) Erectile Dysfunction in Diabetics in Cotonou (Benin). Diabetes \& Metabolism, 30, 1 S71.

[7] Costa, P., Avances, C. and Wagner, L. (2003) Erectile Dysfunction: Knowledge, Wishes and Attitudes. Results of a French Survey of 5099 Men Aged 18 to 70 Years. Progress in Urology, 13, 85-91.

[8] Selvin, E., Burnett, A.L. and Platz, E.A. (2007) Prevalence and Risk Factors for Erectile Dysfunction in the US. The American Journal of Medecine, 120, 151-157. http://dx.doi.org/10.1016/j.amjmed.2006.06.010

[9] Ab Rahman, A.A., Al-Sadat, N. and Low, W.Y. (2011) Prevalence of Erectile Dysfunction in Primary Care Setting Malaysia. JMH, 1, 50-53. http://dx.doi.org/10.1016/s1875-6867(11)60021-3

[10] Siu, S.C., Lo, S.K., Wong, K.W., Ip, K.M. and Wong, Y.S. (2001) Prevalence of and Risk Factors for Erectile Dysfunction in Hong Kong Diabetic Patients. Diabetic Medicine, 18, 732-738. http://dx.doi.org/10.1046/j.0742-3071.2001.00557.x 
[11] Giuliano, F., Chevret-Measson, M., Tsatsaris, A., Reitz, C., Murino, M. and Thonneau, P. (2002) Prevalence of Erectile Dysfunction in France: Results of an Epidemiological Survey of a Representative Sample of 1004 Men. European Urology, 42, 382-389. http://dx.doi.org/10.1016/S0302-2838(02)00323-8

[12] Diao, B., Ndoye, A.K., Fall, P.A., Niang, L., Odzebe, A., Bah, I., et al. (2007) Erectile Dysfunction in Senegal: Epidemiological Profile. Andrologie, 17, 223-229. http://dx.doi.org/10.1007/BF03040731

[13] Akkus, E., Kadioglu, A., Esen, A., Doran, S., Ergen, A., Anafarta, K., et al. (2002) Prevalence and Correlates of Erectile Dysfunction in Turkey: A Population-Based Study. European Urology, 41, 298-304. http://dx.doi.org/10.1016/S0302-2838(02)00027-1

[14] Scarneciu, I., Lupu, S. and Scarneciu, C.C. (2014) Smoking as a Risk Factor for the Development of Erectile Dysfunction and Infertility in Men; Evaluation Depending on the Anxiety Levels of These Patients. Procedia-Social and Behavioral Sciences, 127, 437-442. http://dx.doi.org/10.1016/j.sbspro.2014.03.286

[15] Gueye, S.M., Diop, S.N., Ba, M., Dagadou, E.K., Fall, P.A., et al. (1998) Erectile Dysfunction in Diabetic Patient. Epidemiological Profile in Senegal. Progress in Urology, 8, 377-381.

[16] El-Sakka, A.I. (2012) Erectile Dysfunction in Arab Countries. Arab Journal of Urology, 10, 97-103. http://dx.doi.org/10.1016/j.aju.2012.01.004

[17] Weinberg, A.E., Eisenberg, M., Patel, C.J., Chertow, G.M. and Leppert, J.T. (2014) Diabetes Severity, Metabolic Syndrome, and the Risk Erectile Dysfunction. Journal of Sexual Medicine, 10, 3102-3109. http://dx.doi.org/10.1111/jsm.12318

[18] Kolodny, R.C., Goldstein, H.H., Barnet, D.N. and Kahn, B. (1974) Sexual Dysfunction in Diabetic Men. Diabetes, 23, 306-309. http://dx.doi.org/10.2337/diab.23.4.306

[19] Moreira, E.D., Lôbo, C.F.L., Diament, A., Nicolosi, A. and Glasser, D.B. (2003) Incidence of Erectile Dysfunction in Men 40 to 69 Years Old: Results from a Population-Based Cohort Study in Brazil. Urology, 61, 431-436. http://dx.doi.org/10.1016/S0090-4295(02)02158-1

[20] Ossou-Nguiet, P.M., Odzébé, A.S.W., Bandzouzi-Ndamba, B., Banzouzi, L.F., Gnonlonfoun, D., Bouya, P.A., et al. (2012) Erectile Dysfunction after Cerebral Vasculary Accident in Brazzaville. Revue Neurologique, 168, 538-542. http://dx.doi.org/10.1016/j.neurol.2012.04.001

[21] Vlachopoulos, C.V., Terentes-Printzios, D.G., Ioakeimidis, N.K., Aznaouridis, K.A. and Stefanadis, C.I. (2013) Prediction of Cardiovascular Events and All-Cause Mortality with Erectile Dysfunction: A Systematic Review and MetaAnalysis of Cohort Studies. Circulation: Cardiovascular Quality and Outcomes, 6, 1-11. http://dx.doi.org/10.1161/CIRCOUTCOMES.112.966903

[22] Banks, E., Joshy, G., Abhayaratna, W.P., Kritharides, L., Macdonald, P.S., Korda, R.J. and Chalmers, J.P. (2013) Erectile Dysfunction Severity as a Risk Marker for Cardiovascular Disease Hospitalisation and All-Cause Mortality: A Prospective Cohort Study. PLoS Medicine, 10, e1001372. http://dx.doi.org/10.1371/journal.pmed.1001372

[23] Ridwan, S., Irving, J., Fishman, M.D., Carolyn, S.A.J. and Kay, D. (1991) Cigarette Smoking and Other Vascular Risk Factors in Vasculogenic Impotence. Urology, 38, 227-231. http://dx.doi.org/10.1016/S0090-4295(91)80350-G

[24] Low, W.Y. (2002) What Malaysian Women Believe about Viagra: A Qualitative Inquiry. The Aging Male, 5, 57-63. http://dx.doi.org/10.1080/tam.5.1.57.63

[25] Lemaire, A., Grivel, T., Costa, P., Lachowsky, M. and Elia, D. (2006) Erectile Dysfunction, Sexuallity and SocioCultural Influence. Gynécologie Obstétrique \& Fertilité, 34, 1154-1160. http://dx.doi.org/10.1016/j.gyobfe.2006.10.008 